\title{
An Index of Competition Reduces Statistical Variability and Improves Comparisons between Genotypes of Miscanthus
}

\author{
H. W. Zub • H. Monod • L. Béthencourt • \\ M. Brancourt-Hulmel
}

Published online: 14 April 2012

(C) The Author(s) 2012. This article is published with open access at Springerlink.com

\begin{abstract}
It is important for breeders and producers to be aware of competition effects for variety trials. We aimed at developing an index of competition to reduce statistical variability in field trials and improve comparisons between genotypes of Miscanthus. Twenty-one clones belonging to four species of Miscanthus (M. x giganteus, M. floridulus, M. sinensis, and M. sacchariflorus) planted at the same density were compared at two harvest dates during the second and third crop years. Aboveground volume was shown to be a good predictor of the aboveground biomass of the clones, and was analysed for the competition effect. The best competition index was the ground area occupied by the eight neighbour plants, among the four indices defined as covariates in the statistical models. It reduced the root mean square error of the aboveground volume by as much as $17 \%$, explaining up to $36 \%$ of the residual error of the model. Our results then concerned the contribution of intragenotypic competition of Miscanthus to the variability between plants of a same clone during field trials, the relationship between competition ability and plant traits, and the comparison of genotypes regarding this competition. All clones showed negative competition sensitivities
\end{abstract}

Electronic supplementary material The online version of this article (doi:10.1007/s12155-012-9193-3) contains supplementary material, which is available to authorized users.

H. W. Zub • L. Béthencourt • M. Brancourt-Hulmel $(\bowtie)$

UMR 1281 Stress Abiotiques et Différenciation des Végétaux cultivés, INRA,

BP 50136, 80203 Estrées-Mons, Péronne, France

e-mail: brancour@mons.inra.fr

H. Monod

INRA, Unité de Mathématiques

et Informatique Appliquées (UR341),

Domaine de Vilvert,

78352 Jouy en Josas, France depending on harvest date, crop year, and clone. The competition effects lead to reduction in mean aboveground volume by up to $17 \%$. Competition sensitivities were strongly correlated with aboveground development (height and yield) in both crop years, whatever the harvest dates. In Miscanthus field trials, using a competition index may help to reduce statistical variability and improve comparisons between genotypes.

Keywords Miscanthus $\cdot$ Field trials $\cdot$ Intragenotypic competition · Competition effect · Competitive ability . Aboveground biomass

\section{Introduction}

Miscanthus is a genus of tall, perennial, rhizomatous $\mathrm{C}_{4}$ grass harvested annually, mostly for bio-energy purposes. Two harvest dates are considered: (i) the autumn harvest during the flowering phase at maximum yield, hypothesized as being favourable for bioethanol production [1, 2], and (ii) the winter harvest at the end of winter after leaf loss and nutrients translocation into the rhizome, more favourable for the environment and combustion [3]. Most studies performed in Europe involved a single clone of Miscanthus $x$ giganteus [4] because of its high potential for biomass production in temperate climates [5]. Some Miscanthus breeding programs are improving Miscanthus $x$ giganteus and another species like M. sinensis [6-8] to enlarge the varietal offer for various climates and uses.

In trials for new genotypes, several studies estimated variability in biomass yields of different Miscanthus species in Europe [9-13]. These studies found differences between genotypes in aboveground biomass yield, estimated on four to 16 plants per plot $[9,11,12]$. Nevertheless, a high 
statistical variability occurred between plants within a given Miscanthus genotype in past studies. For instance, Jorgensen [9] found that the mean dry matter yield of M. $x$ giganteus in October of its second crop year was $20 \pm 8.8$ t.ha $^{-1}$. Such a high statistical variability can hamper the comparisons between genotypes.

In plant breeding, there are two kinds of competition effects: (1) competition between several genotypes (i.e., intergenotypic competition [14]), and (2) competition within genotypes (i.e.,intragenotypic competition [15]). The first one compares plots between genotypes, whereas the second compares plants within a plot for a given genotype. In Miscanthus, Meyer et al. [16] studied competition between genotypes, and predicted the outcome of Miscanthus and Switchgrass surviving together in a natural setting from competitive abilities studied in greenhouse conditions. In field experiments, no information about intragenotypic competition exists, although it may contribute to explaining the statistical variability of some results.

It may therefore be useful to compare Miscanthus behaviour with that of forest trees where intensive research exists with regard to the development of competition indexes and their contribution to reduce the bias and the variability in the assessment of genotype performance, especially in smaller plants $[17,18]$.

Due to the existence of a rhizome remaining underground for several years, the development of Miscanthus may be more similar to that of trees than of annual crops. In the same way, the usual planting density of 2 plants. $\mathrm{m}^{-2}$ [13] is relatively low when compared with that of annual species, and thus it is more comparable to the density of perennial forestry species.

In most cases, competition corresponds to an interaction between plants, and results from a shared requirement for limited resources in the environment [19]. Competition ability includes both competitive effects and response to depletion in the supply of resources. It is due to several plant traits that control resource uptake and use efficiency [20-22]. The response to competition varies at the species level: dominated species that get reduced survival, growth, and/or reproduction whereas dominant species get identical or increased survival, growth, and/or reproduction [23]. In the context of plant breeding, such plant-to-plant interactions can lead to false estimates and increase variability in the assessment of genotype performance, especially in small plots.

In field, trials have compared the growth of genotypes under different competition situations and the interactions that occur between neighbouring plots; i.e., growth interactions between different genotypes [17]. A border row usually prevents any bias from affecting genotype performance assessment, but the extent of the interaction is often unknown, and it could influence several individuals and rows
[24]. One strategy is to plant individuals in a compact plot (in the same way as for an annual crop) and then to study the centre of the plot [24]. It is also possible to incorporate a covariate in the statistical model, in order to control competition by adding elements such as the type and/or size of neighbouring plants [25]. This covariate corresponds to a competition index that can characterize the status of competition of a target plot by comparison with its neighbouring plots $[24,26]$. Studying plants instead of plots allows the study of intragenotypic competition. By contrast, few studies have used these indices to study intragenotypic competition [18, 27-31], but they were often reduced to studying plant-to-plant interactions in a stand containing a single genotype [31]. These indices were used notably to summarize, interpret and explain the results with regard to individual tree growth in a wide variety of species (e.g., Tsuga heterophylla, Thuja plicata, Pinus nigra or Picea abies) and growth conditions ([18, 27-30] respectively). According to Weiner et al. [32], the influence of neighbouring plants can vary as a function of distance from the target plant or the diameter of neighbouring plants. A competition index is determined as a function of the size of the target plant and neighbouring plants, and takes account of the distance between the target plant and its neighbours. These indices can combine multiple primary measures. Many studies have compared distance-dependent indices with distance-independent indices [18, 28, 33-35], and concluded that they contribute to only a minor improvement in modelling accuracy when compared with distance-independent indices.

The study of intragenotypic competition in Miscanthus may enable a clearer understanding of the high degree of variability between plants in the same plot. Moreover, variations of competition effect for clones, harvest dates, and crop years may explain the differences in variability observed between these factors. Taking account of competition in genetic diversity, analyses may also reduce the plot variability and the variability that affects statistical analyses.

Since a high statistical variability occurred in past studies between plants within a given Miscanthus genotype, the aim of this paper was to develop an index of competition to reduce statistical variability in field trials and improve comparisons between genotypes of Miscanthus. We based our objective on two main hypotheses. We predicted that in Miscanthus, there would be intragenotypic variability large enough to give false estimates of the worth of the genotypes. Further, we predicted that we could construct an index to estimate competitive ability to improve comparisons between genotypes. We therefore defined how competition between plants could explain variability in the behaviour of plants belonging to the same clone in the field, i.e., intragenotypic competition, and we compared genotypes with respect to this intragenotypic competition effect. We studied four Miscanthus species, and we finally correlated 
the competition effect $(\mathrm{Cg})$ with plant characteristics, particularly with aboveground volume and with biomass yield.

\section{Materials and Methods}

\section{Site and Trial Descriptions}

The experiment was set up at the INRA experimental unit in Mons $\left(49^{\circ} 53 \mathrm{~N}, 3^{\circ} 00 \mathrm{E}\right)$, Northern France during the spring of 2007. The experimental field was composed of deep loam soil (Ortic luvisol, FAO classification). A meteorological station recorded rainfall and radiation at a distance of $1 \mathrm{~km}$ from the field trial. Four and one thermistances within the trial plot recorded rhizome temperature (at $20 \mathrm{~cm}$ under the soil surface) and air temperature (at $10 \mathrm{~cm}$ above the soil surface) respectively.

The trial was composed of 21 clones: three clones that were inter-specific hybrids, two of which were identified as M. x giganteus, 15 clones of $M$. sinensis, two clones of $M$. sacchariflorus, and one clone of M. floridulus (genotype characteristics are available in supplemental data). Rhizomes were obtained from mother rhizomes, and were acquired from different suppliers. Their size was equalized as much as possible before planting. They were planted by hand at a density of 2 plants. $\mathrm{m}^{-2}$ in a randomized complete block design with six replicates (three always harvested in autumn, and three others always harvested in winter). Each plot consisted of 32 plants (four rows of eight plants) of a same clone, separated from neighbouring plots by two rows of a single border clone of $M$. sinensis (see Fig. 1a for details). The Malepartus clone of M. sinensis species was preferred for border plots because of its intermediate aboveground development compared with other clones in the study. The border genotype was planted in the spring of 2008 , and developed little during the vegetative periods of 2008 and 2009. The spacing of plants was $0.8 \mathrm{~m}$ between rows (i.e., between planting rows) and $0.6 \mathrm{~m}$ between positions (i.e., within planting rows). Four thousand and thirtytwo plants were observed, which corresponded to 32 plants/ plot $\times 6$ repetitions $\times 21$ genotypes.

To prevent any gap in the plant rows due to the nonemergence of some plants, all the clones were established in a field nursery. It was close to the trial, and planted at the same time in spring 2007. During September 2007, a transfer of plants was done from this nursery to the trial to cover any missing areas within the four rows of the plots.

\section{Plant Measurements}

The plant measurements covered a period of 3 years (2007 to 2009).

The number of stems per plant (NS) and the vegetative plant height $(\mathrm{H}, \mathrm{cm})$ concerned the measurements of all plants prior to harvest. Vegetative plant height corresponded to the distance from the ground to the ligula of the last ligulated leaf. Three hundred stems per plot for each clone were randomly chosen for the stem diameter measure. It referred to the larger section at an average of $5 \mathrm{~cm}$ above soil of a sample. The ground occupied per plant $\left(\mathrm{SA}, \mathrm{cm}^{2}\right)$ and
Fig. 1 a Plant positions within two adjacent plots and their borders. b Position of the eight direct neighbouring plants (I), of the nearest two direct plants in the same row (2); of the two direct plants in the same line (3) and of the four direct plants (4) defined in (2) and (3) used to calculate the competition index of the 12 central plants

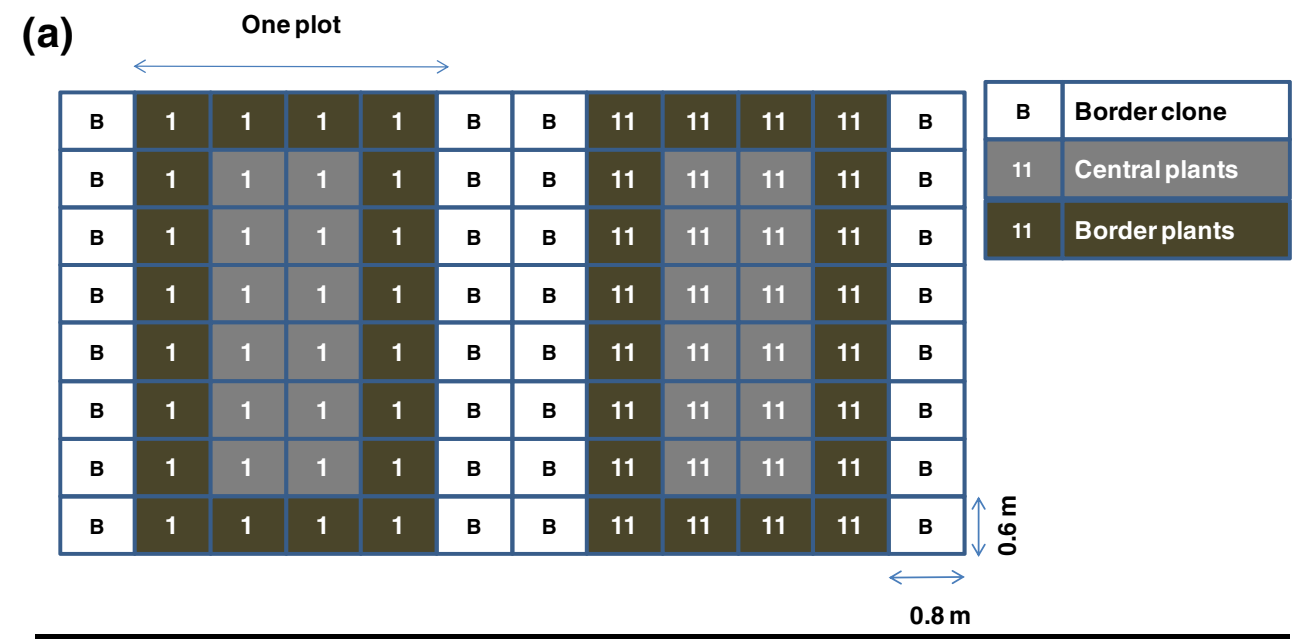

(b)
(1)

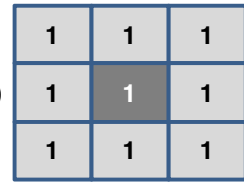

(2)

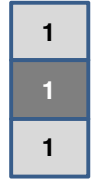

(3)

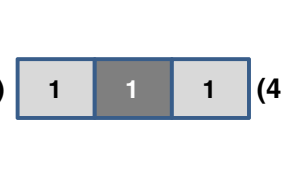

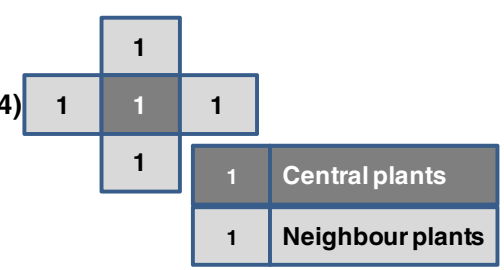


the aboveground volume per plant $\left(\mathrm{AV}, \mathrm{cm}^{3}\right)$ were then calculated according to Eqs. (1) and (2):

$S A=N S *\left[\left(\frac{S D}{2}\right)^{2} \pi\right]$

$A V=S A * H$

During the third crop year (2009), it was not possible to distinguish plants on the plots of the two M. sacchariflorus clones, since they had creeping-rhizomes. In these cases, it corresponded to missing data.

During the first crop year (2007), the harvest of all plants took place in February. During the second and third crop years, the "autumn harvest" corresponded to three blocks. Their harvest occurred always after the vegetative period in September-October 2008 and 2009. This enabled an estimate of the maximum aboveground biomass yield. The "winter harvest" corresponded to the three remaining blocks. Their harvest was after the winter (in January-February 2009 and 2010). This enabled an estimate of the aboveground biomass yield usually observed in a cropping environment. We evaluated the characteristics of the most frequent plants per plot for genotype: it consisted of eight plants out of 32 individually harvested from each plot, these being plants in which the stem number (NS) was closest to the NS plot median. The assessment of aboveground fresh weight and the moisture content by drying at $100{ }^{\circ} \mathrm{C}$ during 48 hours concerned each plant of the eight sampled plants, and it made it possible to determine biomass yield (expressed in tonnes of dry matter per hectare).

Within each small plot, two types of plants made it possible to study intragenotypic competition and to avoid missing values for plants located near the border plants. We used the 12 central plants (Fig. 1a) of the plot to calculate competition indices and to study competition variability between genotypes, since all these plants had a complete neighbourhood (Fig. 1b-1). We used the border plants (Fig. 1a) of the plot only to calculate competition indices.

\section{Calculation of the Competition Index}

Four competition indices (CI) were calculated for the 12 central plants of the plot in order to assess the competition effects directly. Their assessment followed Eq. (3) during the second and third crop years:

$C I_{8}(X)_{l}=\sum_{v=1}^{8} X_{v}$

where the sum is over the eight direct neighbouring plants (1) of the central plant $l$ and $X$ corresponds to one characteristic of these plants: stem number (NS), total plant height $(\mathrm{H})$, area of ground occupied by one plant (SA) or aboveground volume
(AV). Three other combinations of surrounding plants were tested: (2) the nearest two direct plants in the same row, (3) the nearest two direct plants in the same line, and (4) the four direct plants defined in (2) and (3). The results focused on the eight neighbouring plants, because the other combinations were much less significant (see Fig. 1.b for details).

In some cases, there was no neighbour and a value of 0 was assigned for the stem number, the plant height, the area of ground occupied by one plant, and the aboveground volume.

Statistical Analyses

SAS software allowed performing all statistical analyses [36].

Due to the high number of plants observed, a preliminary objective was to determine an "easy-to-measure" plant characteristic that best predicted plant biomass yield in order to make the study feasible, and that would be available for the 4,032 plants. For each crop year and for each date of harvest, correlation coefficient assessments concerned the biomass yield $(\mathrm{Y})$ and plant characteristics (NS, SA, AV, SD and height), as previously defined. To quantify this relationship, we used two correlation coefficients: (i) the mean intragenotypic correlation, defined as the average of the Pearson correlation coefficients calculated with the eight plants harvested within each plot, and (ii) the intergenotypic correlation, defined as the Pearson correlation coefficient based on the genotype means.

The predictor for studying competition on yield corresponded to the characteristic displaying the highest intragenotypic correlation.

We considered the 12 central plants of the plot for which the neighbourhood was entire (Fig. 1a) in order to evaluate the influence of intragenotypic competition on the performance of individual clones. Each plant was characterized by the corresponding genotype $\mathrm{g}$, by the block $\mathrm{k}$ and by its spatial position into the field $(\mathrm{i}, \mathrm{j})$, with $\mathrm{i}$ corresponding to the number of rows and $j$ the number of lines of the field. For each harvest date and each crop year, a three-step analysis was necessary on individual observations:

a) Analysis of variance was first realised, with no competition included in the model. The model was:

$$
\text { Model (1) } Y_{i j g k l}=\mu+\rho_{i}+\pi_{j}+\alpha_{g}+\beta_{k}+\omega_{g k}+\varepsilon_{i j g k l}
$$

where $\mathrm{Y}_{\mathrm{ijgkl}}$ is the performance (NS, height, $\mathrm{SA}$ or $\mathrm{AV}$ ) of the central plant $l$ at the field position $(\mathrm{i}, \mathrm{j})$ and belonging to genotype $g$ in block $k, \mu$ is the general mean, $\rho_{i}$ is the random effect of the row $i, \pi_{j}$ is the random effect of the lines $\mathrm{j}, \alpha_{g}$ is the genotype main effect, $\beta_{k}$ is the effect of block $k, \omega_{g k}$ is the random plot effect, and $\varepsilon_{i j g k l}$ is the first residual term. Note that the random plot effect $\omega_{g k}$ may include both genotype $\times$ block interaction and plot-scale variability. Model (1) corresponded to a baseline reference. 
A Student-Newman-Keuls (SNK) multiple range test determined the significant differences.

b) The $\mathrm{CI}_{8} \mathrm{X}$ competition indices were then introduced as covariates in the analysis of variance, according to the model:

$$
\begin{gathered}
\text { Model (2) } Y_{i j g k l}=\mu+\rho_{i}+\pi_{j}+c_{g}+C I_{8}(X)_{l}+\alpha_{g}^{\prime}+ \\
\beta_{k}+\omega_{g k}+\varepsilon_{i j g k l}^{\prime}
\end{gathered}
$$

where $c_{g}$ is the competition sensitivity of clone $g$ and $\mathrm{CI}_{8}(\mathrm{X})_{l}$ is the competition index (CI) calculated using previous Eq. (3) for each plant. $\varepsilon_{i j g k l}$ is the second residual term. Note that $c_{g}$ depends on the clone $\mathrm{g}$ and is usually negative, and so the competition effect $c_{g} C I_{8}(X)_{l}$ is a loss of performance due to neighbour.

Each combination of harvest date and crop year was run in a separate analysis, because our prior analyses had revealed that date of harvest and crop year had a highly significant effect $(p<0.0001)$ on plant performance (NS, height, SA and AV). The efficiency of each index was summarised by the percent of reduction in the root mean squared error (RMSE) between model (1) and model (2), these RMSE depending respectively on the first residual term and the second residual term. Coefficients of determination $\left(R^{2}\right)$ and coefficients of variation were also calculated. In addition, we used Akaike's (1987) information criterion (AIC) for comparing models with different numbers of parameters. The model with the minimum AIC value corresponded to the best model to fit the data.

The efficiency of the competition effect explained the residual variability by:

Efficiency $=\frac{\operatorname{SSR}(1)-\operatorname{SSR}(2)}{\operatorname{SSR}(1)}$ where $\operatorname{SSR}(1)$ is the residual sum of square of model (1) depending on the first residual term, and $\operatorname{SSR}(2)$ is the residual sum of square of model (2) depending on the second residual term.

c) The $c_{g}$ competition sensitivity parameters $c_{g}$ were assessments from the best "competition model", that is, the version of model (2) selected in step b). For each crop year and each harvest date, the Pearson correlations were calculations between the competition sensitivity parameters $c_{g}$ and mean aboveground volume of genotype $g$ on one hand, and biomass yield on the other hand.

\section{Results}

Preliminary Analyses

Preliminary analyses aimed at identifying which measured characteristics of the plant could be useful as a predictor of biomass yield, among stem number (NS), total plant height, occupied area of ground (SA) and aboveground volume $(\mathrm{AV})$. The random effects of row and lines were nonsignificant whatever the harvest date and crop year (data not shown). The following analyses removed them to simplify the model.

\section{Identification of Aboveground Volume as the Best Predictor of Aboveground Yield}

At the intragenotypic level (Table 1), the strongest positive relationships stood out between the biomass yield and the aboveground volume whatever the crop year. During the second crop year, the mean intragenotypic correlation

Table 1 Intragenotypic and intergenotypic correlations between aboveground biomass yield and plant traits in autumn and winter harvest dates

\begin{tabular}{|c|c|c|c|c|c|}
\hline & \multirow[t]{2}{*}{ Plant traits } & \multicolumn{2}{|l|}{ Year 2} & \multicolumn{2}{|l|}{ Year 3} \\
\hline & & Autumn harvest & Winter harvest & Autumn harvest & Winter harvest \\
\hline \multirow[t]{4}{*}{ Intragenotypic correlation } & NS & $0.62(18 *)$ & $0.76\left(20^{*}\right)$ & $0.59\left(16^{*}\right)$ & $0.65\left(17^{*}\right)$ \\
\hline & Height & $0.49\left(14^{*}\right)$ & $0.62\left(17^{*}\right)$ & $0.36(8 *)$ & $0.48\left(13^{*}\right)$ \\
\hline & SA & $0.62\left(18^{*}\right)$ & $0.76\left(20^{*}\right)$ & $0.64\left(17^{*}\right)$ & $0.65\left(17^{*}\right)$ \\
\hline & $\mathrm{AV}$ & $0.70\left(17^{*}\right)$ & $0.82\left(19^{*}\right)$ & $0.69\left(17^{*}\right)$ & $0.73\left(17^{*}\right)$ \\
\hline \multirow[t]{4}{*}{ Intergenotypic correlation } & NS & -0.18 & -0.07 & -0.28 & -0.08 \\
\hline & Height & $0.82 *$ & $0.92 *$ & $0.91 *$ & $0.91 *$ \\
\hline & SA & $0.89 *$ & $0.90 *$ & $0.83 *$ & $0.92 *$ \\
\hline & $\mathrm{AV}$ & $0.96 *$ & $0.97 *$ & $0.92 *$ & $0.98 *$ \\
\hline
\end{tabular}
during the second and third crop year

Intragenotypic correlation, means of 21 Pearson correlation coefficients $(r)$ calculated from individual observations by clone (number of clone that presents a significant correlation, ${ }^{*}$ significant correlation at level of $5 \%$ )

Intergenotypic correlation, Pearson correlation coefficient $(r)$ calculated from mean clone performance observations

NS, stem number; SA, ground area; AV, aboveground volume 
coefficient $(r)$ was equal to 0.70 and 0.82 for autumn and winter harvests respectively. During the third crop year, it was similar to the second crop year. These high positive significant correlations (at 0.05 probability level) seemed to be mainly due to the high correlation observed between the biomass yield and the stem number.

At the intergenotypic (between genotypes) level (Table 1), the highest observed correlations were also those between the mean biomass yield and the mean aboveground volume. These high positive correlations were mainly due to the high correlation between the mean biomass yield and the mean height of plants. Interestingly, in opposite to intragenotypic level, the stem number in not correlated to biomass yield.

The correlations between the mean biomass yield and the mean area of ground occupied by a single plant were high and positive for both intra- and intergenotypic levels. The difference in stem diameter between clones for intergenotypic level and by difference in stem number between plants for intragenotypic level could explain them (data not shown). The area of ground occupied by one plant varied in line with stem diameters. For instance, during the second year, although clones Aug and H6 had the same mean number of stems, the mean area of ground occupied by one plant was higher for clone H6 than for clone Aug because the stem diameter of clone H6 was higher than the stem diameter of clone Aug $(5.8 \mathrm{~mm}$ versus $4 \mathrm{~mm}$ respectively).

Thus, whatever the harvest date and crop year, aboveground volume (AV) was highly correlated with biomass yield. It was also a synthetic measure of height and occupied area of ground. Consequently, we chose $\mathrm{AV}$ as the predictor of biomass yield to compare the clones.

\section{Clonal Aboveground Volume Strongly Depended on Harvest Date and Crop Year}

Clones differed significantly in terms of their individual aboveground volume whatever the harvest date or crop year (Table 2). For the second crop year, AV mean was slightly higher for the autumn harvest than for the winter harvest $\left(848 \mathrm{~cm}^{3}\right.$ versus $\left.806 \mathrm{~cm}^{3}\right)$. This difference was reversed and more marked during the third crop year, with a $65 \%$ increase between winter harvest and autumn harvest.

On the autumn harvest plots, AV mean increased by $81 \%$ between second and third crop years. AV means of clones Flo, GigB, GigD, Fer, Fla, Pur, Sil, Str and Yak increased by more than $100 \%$. Clones H6, Gol, Grz, Mal and Rot were stable. AV mean decreased for clone Aug. On the winter harvest plots, the increase between the second and third crop years was four times higher than on the autumn harvest plots. All clones had at least a doubled AV mean in third crop year in comparison with second crop year. The increase of the AV mean between the second crop year and the third crop year was $311 \%$ for all clones. The smallest increase of $97 \%$ concerned clone $\mathrm{Mal}$, and the largest increase of $915 \%$ corresponded to clone Fla.

Model (1) was the reference to observe the variability of individual data. They were more accurate in the third crop year when compared with the second crop year (Table 2). The coefficients of variation were decreased by $16 \%$ on the autumn harvest, and by $24 \%$ on the winter harvest between the two crop years. By contrast, the coefficient of determinations increased by $30 \%$ and by $6 \%$ between the two crop years, in autumn and in winter respectively. For the third crop year, the model fitted better with the AV data for the autumn harvest ( $R^{2}$ of 0.79$)$ than for the winter harvest $\left(R^{2}\right.$ of 0.73$)$, but $\mathrm{CV}$ remained high in both cases $(52 \%$ and $44 \%$ respectively).

\section{Competition Effect Explained Part of the Variability} between Plants in a Plot

Coefficients of variation were high when applying model (1) to the aboveground volume. For autumn harvest, they corresponded to $62 \%$ and $52 \%$ in the second and third crop years respectively, while for winter harvest they corresponded to $58 \%$ and $44 \%$ respectively (Table 3). Whatever harvest date and crop year, model (1) performance improved by including the competition index based on the eight neighbouring plants of either stem number (NS), plant height $(\mathrm{H})$, occupied ground area (SA), or aboveground volume (AV) (Table 3). Akaïke information criterion (AIC), CV, and RMSE decreased systematically when these covariates were included in the model. An improvement in $R^{2}$ values corresponded to values ranging between $+5 \%$ and $+8 \%$. Higher improvements of CV and RMSE values occurred in the third crop year than in the second crop year. In comparison with model (1), the CVs of model (2) decreased by $5 \%$ and $3 \%$ during the second crop year , and $9 \%$ and $6 \%$ during the third crop year, for autumn and winter harvests respectively. CVs remained high during the third crop year, when competition was high (43\% and $38 \%$ for the autumn and winter harvests respectively). Nevertheless, the competition explained more variability effect during the third crop year than during the second crop year.

Competition indices (CIs) calculated from the stem number (NS) and the ground area occupied by neighbouring plants (SA) were the most efficient indices to improve the AIC, RMSE, CV and $\mathrm{R}^{2}$ values of the model (Table 3 ). The best competition index was the ground area (SA) occupied by the eight neighbouring plant (lowest AIC value whatever conditions). Its inclusion in the analysis of aboveground volume using model (2) significantly improved AIC and RMSE. The improvements in model performance achieved by including competition indices based on $\mathrm{AV}$ were substantially similar to those based on NS or SA. Including a CI based on height 
Table 2 High variability of autumn and winter estimated aboveground volumes for the second and third crop years (2008, 2009) of 21 Miscanthus clones grown by INRA in France
Letters a to g correspond to significantly different groups determined using the Newman and Keuls multiple comparison of means test. 0.0001 Significant at the 0.001 level of probability for the factor studied, $n s$ not significant, Mean $A V$ mean of aboveground volume estimated for each clone

\begin{tabular}{|c|c|c|c|c|c|c|c|c|c|c|}
\hline \multirow[t]{3}{*}{ Clones } & \multicolumn{5}{|c|}{ Autumn harvest } & \multicolumn{5}{|c|}{ Winter harvest } \\
\hline & \multicolumn{2}{|l|}{ Year 2} & \multicolumn{2}{|l|}{ Year 3} & \multirow{2}{*}{$\begin{array}{l}\text { Variation } \\
\%\end{array}$} & \multicolumn{2}{|l|}{ Year 2} & \multicolumn{2}{|l|}{ Year 3} & \multirow[t]{2}{*}{ Variation } \\
\hline & Mean A & $\mathrm{cm}^{3}$ & Mean A & $\mathrm{cm}^{3}$ & & Mean A & $\mathrm{cm}^{3}$ & Mean AV & $\mathrm{cm}^{3}$ & \\
\hline Flo & $1,914.3$ & $\mathrm{a}$ & $4,888.9$ & $\mathrm{a}$ & $155 \%$ & $2,230.5$ & $\mathrm{a}$ & $4,713.2$ & $\mathrm{a}$ & $111 \%$ \\
\hline GigD & 1,895 & $\mathrm{a}$ & $5,144.1$ & $\mathrm{a}$ & $171 \%$ & 1,426 & $\mathrm{~b}$ & $4,369.4$ & $\mathrm{a}$ & $206 \%$ \\
\hline H6 & $1,844.5$ & $\mathrm{a}$ & $1,712.3$ & $\mathrm{c}$ & $-7 \%$ & $1,390.5$ & $\mathrm{~b}$ & $3,403.2$ & $\mathrm{~b}$ & $145 \%$ \\
\hline GigB & $1,635.1$ & $\mathrm{a}$ & $4,261.9$ & $\mathrm{~b}$ & $161 \%$ & $1,403.7$ & $\mathrm{~b}$ & $4,977.2$ & $\mathrm{a}$ & $255 \%$ \\
\hline GolD & $1,516.7$ & $\mathrm{a}$ & 1,746 & $\mathrm{c}$ & $15 \%$ & 872.4 & $\mathrm{~cd}$ & $2,986.8$ & $\mathrm{bc}$ & $242 \%$ \\
\hline Gol & $1,475.1$ & $\mathrm{a}$ & $1,588.9$ & $\mathrm{~cd}$ & $8 \%$ & $1,194.9$ & $\mathrm{bc}$ & $3,138.9$ & $\mathrm{bc}$ & $163 \%$ \\
\hline Punk & $1,090.7$ & $\mathrm{~b}$ & 1,515 & $\mathrm{~cd}$ & $39 \%$ & 795.2 & cde & $2,289.8$ & $\mathrm{~cd}$ & $188 \%$ \\
\hline H5 & 998.8 & $\mathrm{~b}$ & & & & $1,332.7$ & $\mathrm{~b}$ & & & \\
\hline H8 & 958.3 & $\mathrm{~b}$ & $1,694.7$ & $\mathrm{c}$ & $77 \%$ & $1,088.1$ & $\mathrm{bc}$ & $4,690.6$ & $\mathrm{a}$ & $331 \%$ \\
\hline Aug & 821.2 & $\mathrm{bc}$ & 585.8 & ef & $-29 \%$ & 606.8 & def & $1,408.1$ & de & $132 \%$ \\
\hline Mal & 794.6 & $\mathrm{bc}$ & 767.1 & ef & $-3 \%$ & $1,155.4$ & $\mathrm{bc}$ & 2,272 & $\mathrm{~cd}$ & $97 \%$ \\
\hline Her & 693.1 & bcd & $1,246.8$ & cde & $80 \%$ & 319.1 & $\mathrm{fg}$ & $1,406.6$ & de & $341 \%$ \\
\hline $\mathrm{Sac}$ & 604 & bcde & & & & 789.4 & cde & & & \\
\hline Pur & 434.9 & cde & 930.2 & def & $114 \%$ & 322.3 & $\mathrm{fg}$ & $1,784.2$ & de & $454 \%$ \\
\hline Str & 431.9 & cde & $1,170.4$ & cde & $171 \%$ & 141.8 & $\mathrm{fg}$ & 694.2 & ef & $390 \%$ \\
\hline Rot & 388.7 & cde & 386.7 & $\mathrm{f}$ & $-1 \%$ & 191.3 & $\mathrm{fg}$ & 874 & ef & $357 \%$ \\
\hline Grz & 373.9 & cde & 383.8 & $\mathrm{f}$ & $3 \%$ & 283.6 & $\mathrm{fg}$ & 850.7 & ef & $200 \%$ \\
\hline Sil & 337.2 & cde & 722.6 & ef & $114 \%$ & 418.3 & efg & 1,623 & de & $288 \%$ \\
\hline Yak & 242.5 & de & 788.2 & ef & $225 \%$ & 84.8 & $\mathrm{~g}$ & 755.2 & ef & $791 \%$ \\
\hline Fer & 192.5 & de & 483.1 & ef & $151 \%$ & 226.2 & $\mathrm{fg}$ & 910.7 & ef & $303 \%$ \\
\hline Fla & 89.3 & $\mathrm{e}$ & 178.9 & $\mathrm{f}$ & $100 \%$ & 27.9 & $\mathrm{~g}$ & 283.1 & $\mathrm{f}$ & $915 \%$ \\
\hline $\begin{array}{c}\text { General } \\
\text { mean }\end{array}$ & 848.5 & & $1,384.2$ & & $81 \%$ & 806 & & $2,281.6$ & & $311 \%$ \\
\hline R-square & 0.61 & & 0.79 & & & 0.69 & & 0.73 & & \\
\hline Root MSE & 522 & & 722 & & & 467 & & 1,006 & & \\
\hline CV (\%) & 62 & & 52 & & & 58 & & 44 & & \\
\hline geno & 0.0001 & & 0.0001 & & & 0.0001 & & 0.0001 & & \\
\hline block & ns & & ns & & & 0.0001 & & 0.0001 & & \\
\hline geno*block & 0.0001 & & 0.0001 & & & 0.0001 & & 0.0001 & & \\
\hline
\end{tabular}

measurements for both dates of harvest and crop years provided smaller improvements. The competition index CI based on SA was preferred for its efficiency and its acquisition simplicity.

\section{Detection of a Relationship Between the Competition} Effects of a Clone and its Aboveground Development

Whatever the clones and crop years, significant and negative neighbouring effects were detected in model (2) with CI calculated from the ground areas occupied by the eight neighbouring plants. The higher the ground area occupied by the eight neighbours surrounding the target plant $l$, the smaller was the aboveground volume of the target plant $l$. Overall, the estimated competition sensitivities $C_{g}$ were higher (in absolute value) in the third crop year than in the second crop year (Fig. 2). A $C g$ of $-39.6 \pm 7.6 \mathrm{~cm}$ was observed for clone Flo at the winter harvest during the second crop year for instance. It reached $-46.7 \pm 9.4 \mathrm{~cm}$ at the winter harvest during the third crop year. The resulting competition effects $c_{g} \mathrm{CI}_{8}(\mathrm{SA})$ led to a reduction of the mean aboveground volume by $12 \%$ and $14 \%$ during the second crop year and the third crop year respectively. Covariates based on the two or four neighbours surrounding plants were similar but less significant (data not shown).

The intergenotypic correlation between $\mathrm{Cg}$ at the autumn harvest and $\mathrm{Cg}$ at the winter harvest was higher in the third crop year (0.71) than in the second crop year $(0.42)$. The correlation between $\mathrm{C}_{\mathrm{g}}$ in the second crop year and $\mathrm{C}_{\mathrm{g}}$ in the third crop year was equal to 0.76 for the autumn harvest and to 0.82 for the winter harvest (Fig. 2).

The intergenotypic correlations between the mean AV of clones and $\mathrm{Cg}$ were high and negative, with values equal to 
Table 3 Aboveground volume model analysis by inclusion of competition index calculated from NS (stem number), height, SA (ground area), and AV (aboveground volume) of the eight neighbouring plants: improvement in CV, $R^{2}$, RMSE, and AIC values at autumn and winter harvests in the second and third years
Autumn harvest

Crop year $\mathrm{Cl}$
Winter harvest

\begin{tabular}{llllllll}
$\begin{array}{l}\text { Efficiency } \\
(\% \mathrm{SSR})\end{array}$ & $P$ & $\mathrm{CV}$ & $R^{2}$ & $\mathrm{RMSE}$ & $\mathrm{RMSE} \%$ & $\mathrm{AIC}$ & $\begin{array}{l}\text { Efficiency } \\
(\% \mathrm{SSR})\end{array}$ \\
\hline
\end{tabular}

\begin{tabular}{|c|c|c|c|c|c|c|c|c|c|c|c|c|c|c|c|}
\hline Year 2 & Model (1) & & 62 & 0.61 & 522 & & $5,455.5$ & & & 58 & 0.69 & 467 & & $4,819.3$ & \\
\hline \multirow[t]{4}{*}{ Model (2) } & NS & 0.001 & 57 & 0.69 & 484 & $7 \%$ & $5,288.8$ & $19 \%$ & 0.001 & 55 & 0.74 & 443 & $5 \%$ & $4,611.9$ & $16 \%$ \\
\hline & Height & 0.001 & 60 & 0.65 & 513 & $2 \%$ & $5,363.4$ & $9 \%$ & 0.001 & 59 & 0.70 & 475 & $-2 \%$ & $4,702.4$ & $3 \%$ \\
\hline & SA & 0.001 & 57 & 0.69 & 484 & $7 \%$ & $5,227.3$ & $19 \%$ & 0.001 & 55 & 0.74 & 443 & $5 \%$ & $4,546.7$ & $16 \%$ \\
\hline & $\mathrm{AV}$ & 0.001 & 57 & 0.69 & 483 & $8 \%$ & $5,427.1$ & $19 \%$ & 0.001 & 55 & 0.75 & 440 & $6 \%$ & $4,731.2$ & $17 \%$ \\
\hline Year 3 & Model (1) & & 52 & 0.79 & 722 & & $5,025.4$ & & & 44 & 0.73 & 1006 & & $5,046.5$ & \\
\hline \multirow[t]{4}{*}{ Model (2) } & NS & 0.001 & 43 & 0.87 & 598 & $17 \%$ & $4,865.4$ & $36 \%$ & 0.001 & 38 & 0.81 & 874 & $13 \%$ & $4,858.5$ & $29 \%$ \\
\hline & Height & 0.001 & 50 & 0.83 & 687 & $5 \%$ & $4,954.8$ & $15 \%$ & 0.001 & 44 & 0.75 & 1003 & $0 \%$ & $4,945.1$ & $7 \%$ \\
\hline & SA & 0.001 & 43 & 0.87 & 598 & $17 \%$ & $4,803.9$ & $36 \%$ & 0.001 & 38 & 0.81 & 874 & $13 \%$ & $4,801.8$ & $29 \%$ \\
\hline & $\mathrm{AV}$ & 0.001 & 43 & 0.87 & 597 & $17 \%$ & $5,002.1$ & $36 \%$ & 0.001 & 38 & 0.81 & 868 & $14 \%$ & $4,988.4$ & $30 \%$ \\
\hline
\end{tabular}

$\mathrm{CI}$, competition index; RMSE, root mean square error; AIC, Akaike information criterion

RMSE \% corresponds to the improvement in the RMSE of the model including the CI compared with the model without the CI, referred to as None

-0.64 and -0.72 for the autumn and winter harvests of the second crop year respectively (Fig. 3a). Values were equal to -0.68 and -0.87 for autumn and winter harvests of the third crop year (Fig. 3b). The greater the aboveground development of a clone was, the more negative its estimated competition sensitivities were. Therefore, clones with a high aboveground development could be dominant with other clones that were smaller for aboveground development. We showed that the correlation between competition sensitivities and yield were similar to those observed between competition sensitivities and aboveground biomass (Fig. 3c, d). Clones displaying higher yields showed the lowest sensitivities to competition (Flo, GigB, and H8 on Fig. 3b,d).
We confirmed the good prediction of the yield by the aboveground volume, and showed that the clones with the highest yield are less sensitive to competition than those clones displaying low yield. Whatever the clone and crop year, competition sensitivities were dependent on the mean development of the clone, at least at the aboveground level.

\section{Discussion}

In the context of a field trial, residual model error in the analysis of variance model needs to be low enough to enable the comparisons between genotypes with regard to
Fig. 2 Competition sensitivities $(\mathrm{Cg})$ values estimated by clone during the second crop year were good predictors of the competition sensitivities estimate for the third crop year. Comparisons between significant $\mathrm{Cg}$ values at the autumn harvest (square) and spring harvest (triangle). Filled squares and triangles correspond to significant values at the 0.05 level for at least 1 year. In each case, $\mathrm{Cg}$ values were estimated according to statistical model (2) with the SA covariate

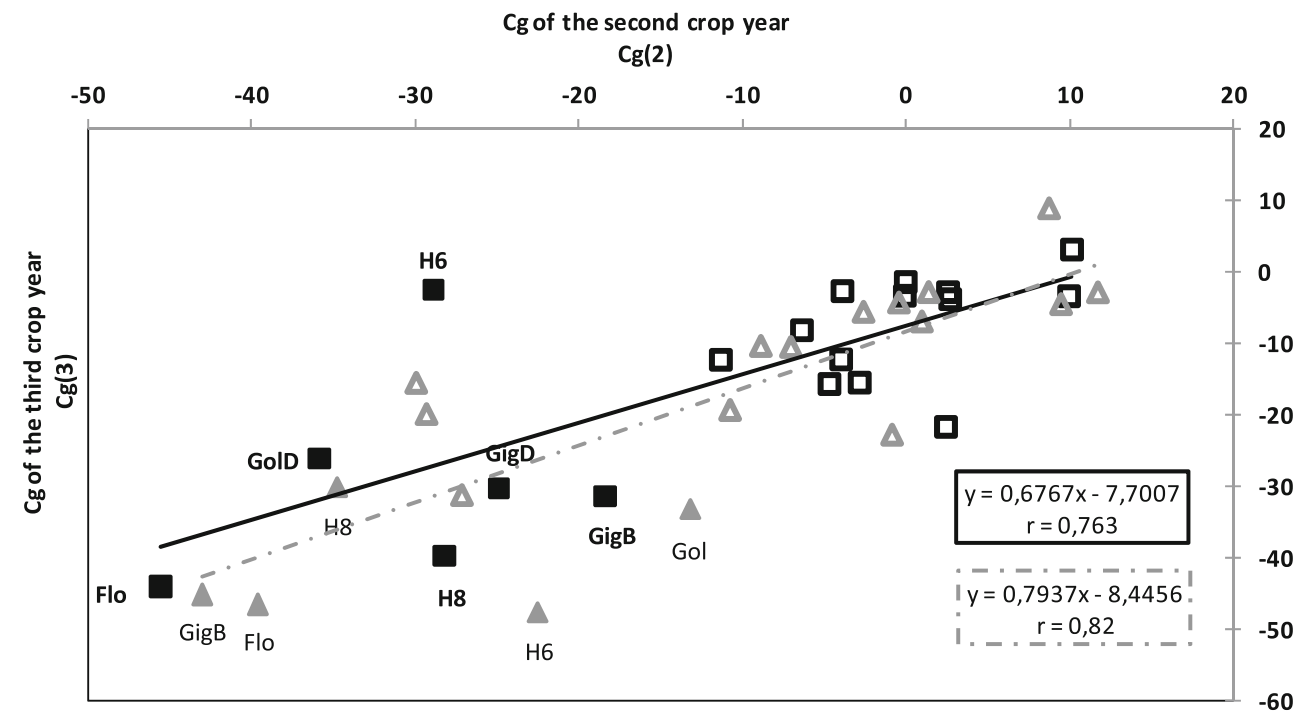

口Autumn Harvest

$\Delta$ Winter harvest 
a
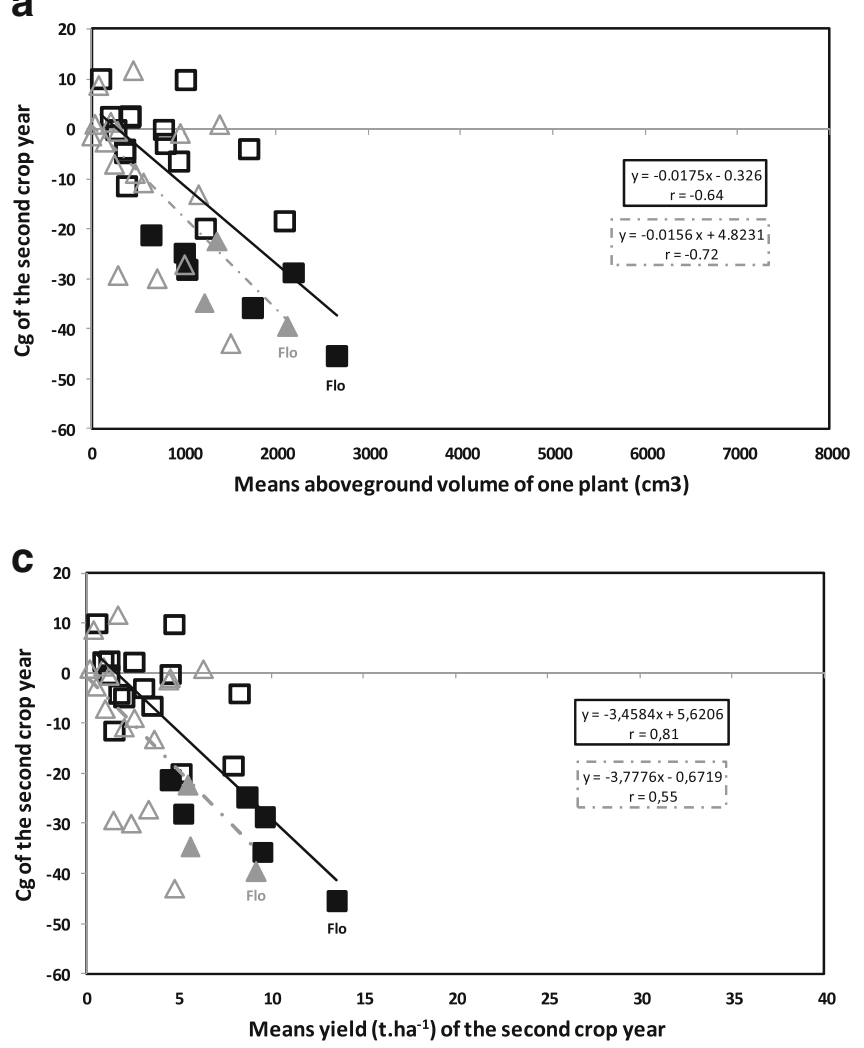

Fig. 3 Relation between the competition sensitivities estimated by clone $(\mathrm{Cg})$ and the mean aboveground volume (AV) of the corresponding clone (a) during the second crop year; (b) during the third crop year. Relation between the competition sensitivities estimated by clone $(\mathrm{Cg})$ and the mean yield of the corresponding clone (c)

quantitative traits. One way to reduce this residual term is to take into account the variability between plants of a plot at the intragenotypic level through intragenotypic competition. In the case of Miscanthus, we observed this type of competition on aboveground volume, and indirectly on biomass yield. Below, we first discuss the reasons for the difference between plants within a clone, and secondly we focus on variations in the importance of competition as a function of the crop year and the harvest date. Finally, we discuss the relationship between sensitivity to competition and the characteristics of the plant.

\section{Competition Effects Explain Part of the Variability between Plants of a Given Clone}

Our prediction that competition effects explain part of the variability between plants of a given clone was supported in the following studies.

We found in this study high coefficients of variation when applying model (1), in particular in crops of Miscanthus of 2 and 3 years old. These variations could be due in large part to competition between plants within a plot. Competition b

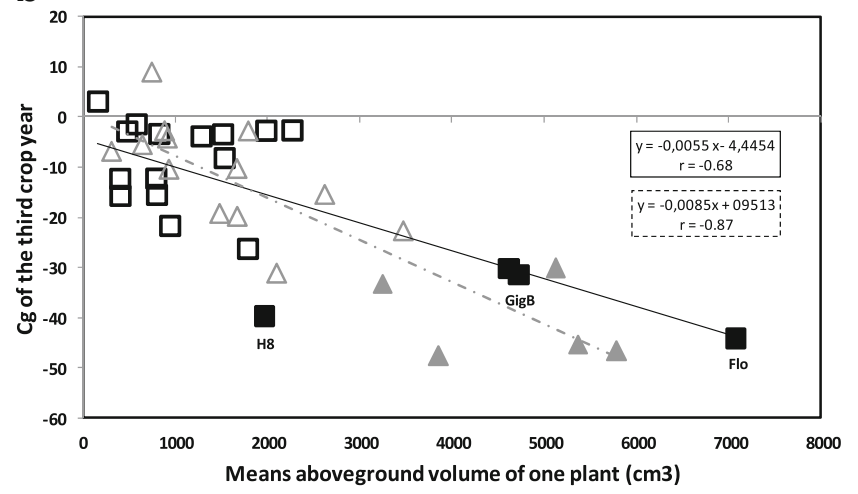

d

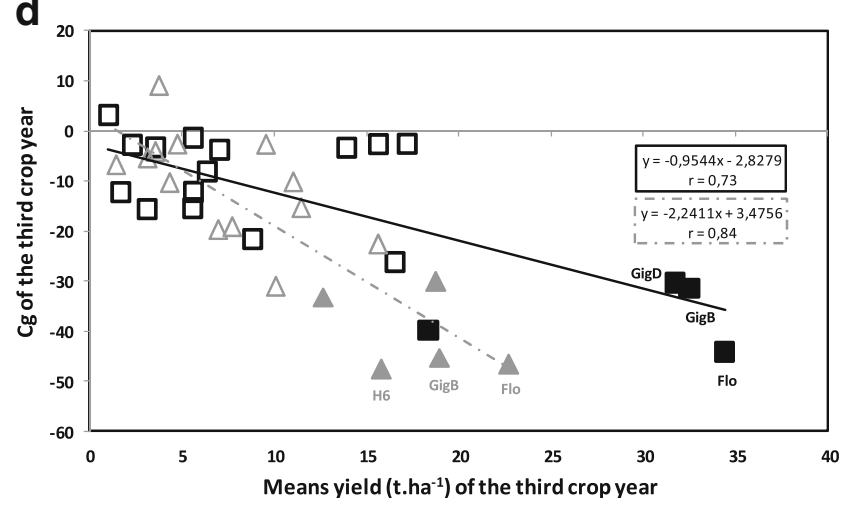

during the second crop year; (d) during the third crop year. Comparisons between $\mathrm{Cg}$ values at the autumn harvest (square) and spring harvest (triangle). Filled squares and triangles correspond to the significant values at the 0.05 level

between plants explains up to $36 \%$ of the differences between plants within a clone in a field trial. As for the allocation of resources, neighbouring plants with similar needs (which is the case in a monoclonal planting scheme) will create interfering areas of influence. The distribution of resources will not remain equal, thus leading to more intense competition situations [29, 37-39]. Weiner and Thomas [40] explained that variations in size among plants should not increase or may even decrease with increased intraspecific competition in clonal plants. The present study has seemed to confirm this hypothesis: we observed a decrease in the coefficient of variation between the two crop years (corresponding to the second and third years of the crops) at the autumn and winter harvests, whatever the clone.

Nevertheless, the studied competition covariates did not explain all the differences between plants, because they were limited to aboveground development. Other factors related to the belowground development should play a role, but have not been investigated yet.

Therefore, reducing the variability of the residual term by accounting for the intragenotypic competition effect should increase the efficiency of breeding new varieties of Miscanthus. 
Intra-species Competition Effects Vary with Crop Year

Intra-genotypic variability was particularly high between seasons/harvests in Miscanthus.

De Luis et al. [27] studied the influence of competition on the growth of a 20-year-old Pinus nigra stand using a regression allometric model. They observed an increase in the competition effect on tree growth when assessed using a coefficient of determination $\left(R^{2}\right)$. It ranged from 0.65 for the first crop year to 0.85 for the fifth crop year, when the stand canopy was "closed". The coefficient of determination then remained stable during subsequent crop years. In our study, we also observed an increase in the competition effect between the second and third crop years. As in trees, competition during the second crop year or during the first year may mostly occur below ground [27], and was therefore not be measured completely by the competition index used. As the $R^{2}$ value was still high during the third crop year, we concluded that competition was an important factor influencing plant performance.

The higher significance of competition sensitivities (and thus of competition effects) observed during the third crop year compared with the second crop year was mainly due to a reduction in the general variability of the plants. We hypothesized that the variability due to the implanted rhizome was too marked during the second crop year to permit any distinction of a competition effect. It is possible that because rhizomes become less variable with crop year, this enables a clearer determination of the competition effect.

This underlines the desirability of reducing residual variability by measuring and taking account of competition effects in evaluation genotypes of Miscanthus in the field.

The Use of Competition Effects with a Simple Variable to Measure

To use competition effects successfully, we need to have a simple variable to measure

Grime (1979, in [41]) associated biomass with an ability to capture resources because it provides a large surface area for uptake. The higher the biomass of a plant is, the stronger its growth is and the smaller the available resources for neighbouring plants are [42]. During our study, we defined aboveground volume as the best predictor of biomass. Our negative correlation between clonal aboveground volume and the clonal neighbourhood effect was consistent with this hypothesis.

The volume of the stand as a measure of above-ground biomass was (is) a simple and practical variable than can readily be used in breeding programs in the field.
Intra-species competition intensity is mainly related to plant size

Size of the plants, or biomass, is not only one of the easiest variables to measure, it is also the most useful physiologically when we consider competition effects.

Plants can compete with each other according to their size. Under asymmetric competition, plants with strong aboveground development exert a disproportionately effect on smaller plants, and may reduce the growth of smaller ones [32]. Under symmetric competition, access to resources is proportional to size [41], and depends on the nutrient uptake capacity of roots and rhizomes. In most cases, competition for light is asymmetric, and competition for nutrients is symmetric. The quantity and quality of light exponentially decrease with distance below the top of the canopy [43]. The taller the plant, the greater the shading of smaller neighbouring plants is, and the higher the degree of asymmetric competition is.

Intragenotypic competition has been symmetric and specific to the size of the species $[44,45]$ because of very small differences in the height of plants of the same genotype. Competition is reliant upon the space occupied by one plant: the more aboveground volume occupied by a single plant, the smaller neighbouring plants will be in compensation, because the nutrient supplies available to all the plants is limited. Our results were consistent with these findings. The competition performance of Miscanthus appeared to be relatively symmetric, i.e., linked to the size of a plant and its eight neighbouring plants. We related competition performance to plant size, especially through the amount of aboveground volume occupied by a plant. We observed correlation coefficients of the same order as those recorded by Gaudet and Keddy [46] between plant traits and competitive ability with regard to 44 wetland plant species in the field (0.74). They were also similar to those observed by Keddy et al. [41] between plant size and the predicted relative competitive performance of 63 pot-grown species of herbaceous plants, compared under two stress conditions (sufficient nutrients and water versus restricted space and nutrient availability, 0.74 and 0.69 respectively).

This is further evidence of the suitability of accounting for biomass in breeding programs for Miscanthus.

\section{Conclusion}

As a result of our experiments, we now have evidence for the perennial grass Miscanthus that taking account of competition effects can improve the efficiency of selection and breeding in the field.

The residual model error in the analysis of variance model needs to be low, to enable the comparisons between genotypes for quantitative traits. In Miscanthus, the present 
results showed that the residual term was quite high during the second and third years of the crop, and could hamper intergenotypic comparisons for traits such as aboveground biomass yield or related traits. Without greater plots or samples (it is indeed important for the breeder and the producer to save place and cost), one way to reduce the residual term is to take into account intragenotypic competition effect in the statistical model, as was done in the present study. As this implies, the observation of all individual plants of a plot, intragenotypic effect assessment requires easy-to-measure variables. Our study showed that it was feasible in Miscanthus, using the stand volume as a predictor of the aboveground biomass.

Because of the strong intragenotypic competition, particularly in large genotypes, the existence of intergenotypic competition might occur. This therefore opens a new window of investigations for Miscanthus in the future, especially in field conditions for multi-species trials and/or multiclone trials.

Furthermore, we suggest that the technique of measuring and accounting for competition effects may be also useful for selection and breeding in other plant species as well as in tree species.

Acknowledgements The authors would like to acknowledge the support they received from the Picardie region (PEL project). They would like to thank David Lindsay for his great suggestions on the manuscript. They appreciated the helpful comments of the editor and the reviewers. They thank Prof. A. Gallais and J.C. Bastien and J. Le Gouis for careful reviewing of the manuscript. They also thank $U$. Jorgensen who provided three clones of Miscanthus. Their thanks also go to S. Arnoult for her management of the experimental field, and M.C. Mansard and A. Obeuf for their valuable assistance with measurements, as well as M. Leleu and the staff of the French experimental unit of INRA's Estrées-Mons.

Open Access This article is distributed under the terms of the Creative Commons Attribution License which permits any use, distribution, and reproduction in any medium, provided the original author(s) and the source are credited.

\section{References}

1. Karp A, Shield I (2008) Bioenergy from plants and the sustainable yield challenge. New Phytol 179:15-32

2. Le Ngoc HT, Rémond C, Dheilly RM, Chabbert B (2010) Effect of harvesting date on the decomposition and saccharification of Miscanthus $\times$ giganteus. Bioressource Technol 101:8224-8231

3. Lewandowski I, Clifton-Brown JC, Andersson B, Basch G, Christian DG, Jorgensen U et al (2003) Environment and harvest time affects the combustion qualities of Miscanthus genotypes. Agronomy Journal 95:1274-1280

4. Greef JM, Deuter M (1993) Syntaxonomy of Miscanthus-XGiganteus Greef-Et-Deu. Angew Bot 67:87-90

5. Heaton EA, Clifton-Brown J, Voigt TB, Jones MB, Long SP (2004) Miscanthus for renewable energy generation: European Union experience and projections for Illinois. Mitig Adapt Strat Global Change 9:21-30
6. Clifton-Brown JC, Lewandowski I (2000) Overwintering problems of newly established Miscanthus plantations can be overcome by identifying genotypes with improved rhizome cold tolerance. New Phytol 148(2):287-294

7. Clifton-Brown JC, Chiang Yu-C, Hodkinson TR (2008) Miscanthus: genetic resources and breeding potential to enhance bioenergy production. In: Vermerris W (ed) Genetic improvement of bioenergy crops. Springer, New York, pp 273-294

8. Farrell AD, Clifton-Brown JC, Lewandowski I, Jones MB (2006) Genotypic variation in cold tolerance influences the yield of Miscanthus. Ann Appl Biol 149(3):337-345

9. Jorgensen U (1997) Genotypic variation in dry matter accumulation and content of $\mathrm{N}, \mathrm{K}$ and $\mathrm{Cl}$ in Miscanthus in Denmark. Biomass Bioenerg 12(1):155-169

10. Jorgensen U, Mortensen J, Kjeldsen JB, Schwarz KU (2003) Establishment, Development and yield quality of fifteen Miscanthus genotypes over three years in Denmark. Acta Agr Scand B-S P 53(4):190-199

11. Clifton-Brown JC, Lewandowski I, Andersson B, Basch G, Christian DG, Kjeldsen JB et al (2001) Performance of 15 Miscanthus genotypes at five sites in Europe. Agron J 93(5): 1013-1019

12. Jezowski S (2008) Yield traits of six clones of Miscanthus in the first 3 years following planting in Poland. Ind Crop Prod 27:65-68

13. Lewandowski I, Clifton-Brown JC, Scurlock JMO, Huisman W (2000) Miscanthus: European experience with a novel energy crop. Biomass Bioenerg 19(4):209-227

14. Azais JM (1987) Design of experiments for studying intergenotypic competition. J R Stat Soc Ser B Methodol 49(3):334-345

15. Andalo C, Goldringer I, Godelle B (2001) Inter- and intragenotypic competition under elevated carbon dioxide in Arabidopsis thaliana. Ecology 82(1):157-164

16. Meyer MH, Paul J, Anderson NO (2010) Competitive ability of invasive Miscanthus biotypes with aggressive switchgrass. Biol Invasions 12(11):3809-3816

17. Kempton RA (1982) Adjustment for competition between varieties in plant breeding trials. J Agr Sci 98:599-611

18. Brodie CL, Debell DS (2004) Evaluation of field performance of poplar clones using selected competition indices. New For 27:201-214

19. Begon M, Harper JL, Townsend CR (1996) Ecology. Blackwell Science, Oxford

20. Tilman D, Wedin D (1991) Plant traits and resource reduction for five grasses growing on a nitrogen gradient. Ecology 72:685-700

21. Canham CD, LePage PT, Coates KD (2004) A neighborhood analysis of canopy tree competition: effects of shading versus crowding. Can J Forest Res 34:778-787

22. Canham CD, Papaik MJ, Uriate M, McWilliams WH, Jenkins JC, Twery MJ (2006) Neighborhood analyses of canopy tree competition along environmental gradients in New England forests. Ecol Appl 16:540-554

23. Begon M, Mortimer M, Thompson DJ (1986) Population ecology, a unified study of animals and plants. Blackwell Science, Oxford, pp 28-52

24. Gezan SA, Macalpine WJ, Shield IF, Welham S (2008) Controlling for competition in neighbouring field plots in a willow (Salix spp.) trial. Aspects Appl Biol 90:181-187

25. Besag J, Kempton RA (1986) Statistical analysis of field experiments using neighbouring plots. Biometrics 42:231-251

26. Zhao D, Borders B, Wilson M, Rathbun SL (2006) Modeling neighborhood effects on the growth and survival of individual trees in a natural temperate species-rich forest. Ecol Model 196:90-102

27. De Luis M, Raventos J, Cortina J, Moro MJ, Bellot J (1998) Assessing components of a competition index to predict growth in an even-aged Pinus nigra stand. New Forests 15:223-242 
28. Corral Rivas JJ, Alvarez Gonzalez JG, Aguirre O, Hernandez FJ (2005) The effect of competition on individual tree basal area growth in mature stands of Pinus cooperi Bloanco in Durango (Mexico). Eur J Forest Res 124:133-142

29. Boyden S, Binkley D, Stape JL (2008) Competition among Eucalyptus trees depends on genetic variation and resource supply. Ecology 89(10):2850-2859

30. Castagneri D, Vacchiano G, Lingur E, Motta R (2008) Analysis of intraspecific competition in two subalpine Norway spruce (Picea abies (L) Karst) stands in Paneveggio (Trento, Italy). Forest Ecol Manag 255:651-659

31. Newton PF, Jolliffe PP (1998) Assessing processes of intraspecific competition within spatially heterogeneous black spruce stands. Can J Forest Res 28:259-275

32. Weiner J, Stoll P, Muller-Landau H, Jasentuliyana A (2001) The effect of density, spatial pattern, and competitive symmetry on size variation in simulated plant populations. Am Nat 158:438-450

33. Daniels RF, Burkhart HE, Clason TR (1986) A comparison of competition measures for predicting growth of loblolly pine trees. Can J Forest Res 16:1230-1237

34. Biging GS, Dobbertin M (1995) Evaluation of competition indices in individual tree growth models. Forest Sci 41:360-377

35. Winberly MC, Bare BB (1996) Distance- dependant and distance independent models of Douglas fir and western hemlock basal area growth following silvicultural treatment. Forest Ecol Manag 89:1-11
36. SAS Institute (1990) SAS/STAT User's guide. Version 6, fourth ed. SAS Institute Inc., Cary NC, pp 893-997

37. Pimentel D (1968) Population regulation and genetic feedback. Science 159:1432-1437

38. Tilman D (1982) Resource competition and community structure. Princeton University Press, Princeton

39. Chesson P (2000) Mechanisms of maintenance of species diversity. Annu Rev Ecol Syst 31:343-366

40. Weiner J, Thomas SC (1986) Size variability and competition in plant monocultures. Oikos 47: 211-222

41. Keddy P, Nielsen K, Weiher E, Lawson R (2002) Relative competitive performance of 63 species of terrestrial herbaceous plants. J Veg Sci 13:5-16

42. Goldberg DE (1990) Components of resource competition in plant community. In: Gracks JB, Tilman D (eds) Perspectives on plant competition. Academic Press, San Diego, pp 27-49

43. Fitter AH, Hay RKM (1983) Environmental physiology of plants. Academic Press, London

44. MacArthur RH (1972) Geographical ecology. Harper and Row, New York

45. Goldberg DE, Wermer PA (1983) Equivalence of competitors in plant communities: a null hypothesis and a field experimental approach. Am J Bot 70:1098-1104

46. Gaudet CL, Keddy PA (1988) A comparative approach to predicting competitive ability from plant traits. Nature 334: 242-243 